\title{
Switching between standard coral reef benthic monitoring protocols is complicated: Proof of concept
}

\author{
Henri Vallès ${ }^{1}$, Hazel A Oxenford ${ }^{\text {Corresp., }}{ }^{2}$, Alex Henderson ${ }^{2}$ \\ ${ }^{1}$ Department of Biological and Chemical Sciences, University of the West Indies, Cave Hill, Barbados \\ ${ }^{2}$ Centre for Resource Management and Environmental Studies, University of the West Indies, Cave Hill, Barbados \\ Corresponding Author: Hazel A Oxenford \\ Email address: hazel.oxenford@cavehill.uwi.edu
}

Monitoring the state of coral reefs is necessary to identify drivers of change and assess effectiveness of management actions. There are several widely-used survey methods, each of which is likely to exhibit different biases that should be quantified if the purpose is to combine datasets obtained via different survey methods. The latter is a particularly important consideration when switching methodologies in long-term monitoring programmes and is highly relevant to the Caribbean today. This is because of the continuing need for regionally comparable coral reef monitoring datasets and the fact that the GCRMN-Caribbean node is now recommending a photoquadrat method over the chain intercept transect method widely adopted by the members of the first truly regional monitoring network, CARICOMP, in the early-1990s. Barbados, a member of the CARICOMP network, has been using a variation of the chain intercept method in its long-term coral reef monitoring programme for more than two decades. Now a member of GCRMNCaribbean, Barbados is considering switching to the photoquadrat method in conformity with other regional members. Since we expect differences between methods, this study seeks to quantify the nature of those differences to inform Barbados and others considering switching methods. In 2017, both methods were concurrently implemented at 21 permanent monitoring plots across three major reef types in Barbados. Differences in \% cover estimates for the six major benthic components, i.e. hard corals, sponges, gorgonians, macroalgae, turf algae, and crustose coralline algae, were examined within and among reef types. Overall, we found a complex pattern of differences between methods that depended on the benthic component, its relative abundance, and the reef type. We conclude that most benthic components would require a different conversion procedure depending on the reef type, and we provide an example of these procedures for Barbados. The factors that likely contribute to the complex pattern of between-method differences are discussed. Overall, our findings highlight that switching methods will be complicated, but not impossible. Finally, our study fills an important gap by underscoring a 
promising analytical framework to guide the comparison of ecological survey methods on coral reefs. 


\section{Switching between standard coral reef benthic monitoring protocols is}

2 complicated: Proof of concept

3

4

5 Henri Vallès ${ }^{1}$, Hazel Anne Oxenford ${ }^{2}$, Alex Henderson ${ }^{2}$

6

$7 \quad{ }^{1}$ Department of Biological and Chemical Sciences, University of the West Indies, Cave Hill, 8 Barbados.

$9{ }^{2}$ Centre for Resource Management and Environmental Studies, University of the West Indies, 10 Cave Hill, Barbados.

11

12 Corresponding author:

13 Hazel Oxenford ${ }^{2}$

14 Email address: Hazel.oxenford@cavehill.uwi.edu 


\section{Abstract}

16 Monitoring the state of coral reefs is necessary to identify drivers of change and assess

17 effectiveness of management actions. There are several widely-used survey methods, each of

18 which is likely to exhibit different biases that should be quantified if the purpose is to combine

19 datasets obtained via different survey methods. The latter is a particularly important

20 consideration when switching methodologies in long-term monitoring programmes and is highly relevant to the Caribbean today. This is because of the continuing need for regionally comparable coral reef monitoring datasets and the fact that the GCRMN-Caribbean node is now recommending a photoquadrat method over the chain intercept transect method widely adopted by the members of the first truly regional monitoring network, CARICOMP, in the early-1990s. Barbados, a member of the CARICOMP network, has been using a variation of the chain intercept method in its long-term coral reef monitoring programme for more than two decades. Now a member of GCRMN-Caribbean, Barbados is considering switching to the photoquadrat method in conformity with other regional members. Since we expect differences between methods, this study seeks to quantify the nature of those differences to inform Barbados and others considering switching methods. In 2017, both methods were concurrently implemented at 21 permanent monitoring plots across three major reef types in Barbados. Differences in \% cover estimates for the six major benthic components, i.e. hard corals, sponges, gorgonians, macroalgae, turf algae, and crustose coralline algae, were examined within and among reef types. Overall, we found a complex pattern of differences between methods that depended on the benthic component, its relative abundance, and the reef type. We conclude that most benthic components would require a different conversion procedure depending on the reef type, and we provide an example of these procedures for Barbados. The factors that likely contribute to the complex pattern of between-method differences are discussed. Overall, our findings highlight that switching methods will be complicated, but not impossible. Finally, our study fills an important gap by underscoring a promising analytical framework to guide the comparison of ecological survey methods on coral reefs.

\section{Introduction}

Monitoring is a fundamental part of resource management, and in the case of coral reefs is critically important for assessing their state and measuring the success of management actions (Flower et al. 2017; Hill \& Wilkinson 2004; Rogers et al. 1994), since coral reefs are not only highly sensitive to a wide array of natural and anthropogenic stressors (Mumby \& Steneck 2008), but are particularly vulnerable to the global climate crisis (Hughes et al., 2018). Within the Caribbean, the need for effective coral reef management interventions guided by standardised monitoring is particularly acute given that the region is experiencing widespread degradation of its reefs (Jackson et al. 2014) whilst also relying heavily on their ecosystem services to support tourism-dependent national economies and local livelihoods (Burke \& Maidens 2004; Mumby et al. 2014).

The use of standardised monitoring approaches is important to minimize method biases and facilitate integration of data at broad spatial and temporal scales (e.g. allowing regional comparisons and tracking of long-term changes) (Lindeman et al. 2001). Standard biophysical methods for surveying reefs exist (e.g. Hill \& Wilkinson 2004; Rogers et al. 1994). Each method has advantages and disadvantages as well as specific biases, which has prompted a large body of work comparing them (Beenaerts \& Vanden Berghe 2005; Dodge et al. 1982; Jokiel et al. 2015; 
59 Leonard \& Clark 1993; Leujak \& Ormond 2007; Nadon \& Stirling 2005; Ohlhorst et al. 1988;

60 Rogers 1998; Rogers 1999; Rogers \& Miller 2001; Weinberg 1981; Wilson et al. 2007).

61 Within the Caribbean, there are several variant methodologies that have been used by regional

62 long-term monitoring programs such as the Caribbean Coastal Marine Productivity Program

63 (CARICOMP; Alcolado et al. 2001), the Atlantic and Gulf Rapid Reef Assessment (AGRRA;

64 Lang et al. 2010) and Reef Check (Hodgson et al. 2006). The chain intercept transect method

65 (sensu Rogers et al. 1994), involving the use of a thin chain draped carefully over the substrate

66 contour to record benthic composition in direct contact with the chain (e.g. Ferreira et al. 2001;

67 Rogers 1999; Rogers et al. 1983; Rogers \& Miller 2001), was adopted in the early 1990s as the

68 standardized methodology to quantify coral reef benthic composition by the first truly regional

69 monitoring network, CARICOMP. These data have contributed to several region-wide studies

70 and provided the first standardized baseline across the Caribbean (Alcolado et al. 2001; Cortés et

71 al. 2019). With the cessation of CARICOMP in 2007 and a strong recommendation from Jackson

72 et al. (2014) that a standard monitoring program must be maintained in the Caribbean, there has

73 been a re-vitalisation of the Caribbean node of the Global Coral Reef Monitoring Network

74 (GCRMN-Caribbean) of the International Coral Reef Initiative (ICRI). In their new biophysical

75 monitoring guidelines, their recommended Level-3 (preferred) method is to use a photoquadrat

76 (PQ) method (GCRMN-Caribbean 2016).

As part of the CARICOMP network, Barbados has been using chain transects for their long-term coral reef monitoring programme for more than two decades, albeit with one relevant modification. In the modified version of the chain intercept transects in Barbados, substrate

80 composition is recorded at regularly spaced points (rather than continuously) along the chain 81 because preliminary surveys in Barbados have indicated that point-intercept sampling along the 82 chain yielded similar results to continuous sampling, while being less time consuming (Allard

83 1994). This chain point-intercept (CPI) method retains a key attribute of chain intercept transects 84 in that it captures information about the three-dimensional structure of the reef benthos (Hill \& 85 Wilkinson 2004; Rogers et al. 1994).

86 Now a member of GCRMN-Caribbean, Barbados is considering switching to the PQ method in 87 conformity with other regional members. Since we expect differences between these two 88 methods, this study seeks to evaluate the potential magnitude and nature of method biases 89 between the chain point-intercept (CPI) methodology used in Barbados and an adapted version 90 of the PQ level-3 methodology recommended by the GCRMN-Caribbean, with a focus on 91 different reef types. Our main focus here is to explicitly assess whether or not PQ data 92 conversion procedures are likely to be needed so that future PQ datasets can be meaningfully and 93 most accurately compared with the existing CPI historical baselines. We do so using the already 94 established and on-going long-term monitoring program of Barbados; thus broader issues 95 pertaining to the development of an adequate coral reef long-term monitoring program (e.g. 96 Aronson et al. 1994; Brown et al. 2004; Green \& Smith 1997; Houk \& Van Woesik 2006) are 97 beyond this study's scope. It is expected that our findings will be relevant to the wider Caribbean 98 community possessing historical datasets and considering this transition.

\section{Methods}

\section{Reef study sites}

101 Barbados is located in the southeastern Caribbean and has a narrow shelf with easily accessible 102 coral reefs all along the sheltered west and semi-sheltered southwest coasts (Fig. 1). These coral 
103 reefs are generally classified into three major types; bank, fringing and patch reefs that differ in 104 physical location (depth, distance from shore) and structure, and in their biological community 105 composition (Brathwaite et al. 2018; Oxenford et al. 2008; Vallès et al. 2019). A total of 47 reef

106 sites spread across these reefs are surveyed every five years as part of the Barbados government's

107 long-term reef monitoring programme initiated in 1987 (CERMES 2018). In this study 21 of

108 these reef sites (seven of each reef type) were selected for comparing the two reef survey

109 methodologies (Fig. 1, Table S1).

\section{Benthic survey methodologies}

111 The linear chain point-intercept transect (CPI) method used by the long-term Barbados Reef

112 Monitoring Programme (BRMP) is reported in detail by CERMES (2018) and summarised in

113 Table S2 and Fig. 2. In short, ten straight-line transects were surveyed at $2 \mathrm{~m}$ intervals within a

$11410 \times 20 \mathrm{~m}$ permanent monitoring plot established at each reef site. A fine brass chain, marked at

$11510 \mathrm{~cm}$ intervals, was subsequently carefully laid along the reef profile under each straight-line

116 transect. The substrate immediately under each $10 \mathrm{~cm}$ chain mark was identified to species level

117 for hard corals, sponges, gorgonians and macroalgae. Turf algae and crustose coralline algae

118 (CCA) were identified only by these broad categories to include the many species within these

119 groups. Note that because the chains are purposely laid to follow the elevation contour of the

120 substrate, they will extend longer than ten meters, typically yielding $>1200$ point records per

121 permanent plot (Table S2).

122 In this study we worked alongside the BRMP survey team from 10 July - 4 Sept 2017 to

123 undertake a photoquadrat (PQ) survey at each of 21 reef sites using a slightly modified version of

124 the Level-3 highly recommended PQ protocol of GCRMN-Caribbean (2016). The orientation,

125 number and length of transects, and total number of photoquadrats were slightly adapted to

126 facilitate an appropriate comparison between the methods within the established $10 \times 20 \mathrm{~m}$

127 permanent monitoring plots, whilst maintaining approximately the same number of data points

128 per reef site for each method (Table S2). The physical setup of the monitoring plot and the two

129 data collection protocols used at each reef site is illustrated in Fig. 2; a more detailed comparison

130 of the methods is summarized in Table S2. Six photoquadrats $(90 \times 60 \mathrm{~cm}$ with a portrait

131 orientation and spaced $110 \mathrm{~cm}$ apart) were taken along each of the same ten $10 \mathrm{~m}$-transects used

132 for the CPI method, plus an additional $10 \mathrm{~m}$-transect following the permanent monitoring plot

133 demarcation rope at the $20 \mathrm{~m}$ mark (Fig. 2). As such, a total of 66 photoquadrats were taken at

134 each monitoring site with an Olympus TG-3 camera in an external Olympus housing using the

135 highest resolution and underwater image settings, and the internal flash for the bank reef sites to

136 compensate for the loss of colour at depth. A $1 \mathrm{~m}$-monopod was used to maintain the camera at a

137 fixed perpendicular distance from the substrate.

\section{Data handling and analysis}

\section{Raw Data Post-Processing}

140 For the CPI method, data were transferred from underwater slates directly to an excel database

141 and were manipulated using the pivot table tool to produce appropriate summary tables. For the

142 PQ method, photographs were post-processed as recommended by the GCRMN protocol using

143 the Coral Point Count with Excel extensions (CPCe) software (Kholer \& Gill 2006) to overlay

14425 random points on each of the 66 images per site, yielding a total of 1650 point records per

145 permanent plot (Table S2). The available categories in the CPCe software were modified to

146 match the species and category codes used in the BRMP database. Photos that were too dark due 
147 to depth, cloud cover or shadow were edited in the photo-editing software Picasa 3.9.140

148 (Google Inc.) to increase brightness and colour saturation and thereby aid in substrate

149 identification.

150 Data aggregation

151 A single benthic component \% cover value was obtained from each permanent plot. This was

152 achieved by simply dividing the total number of point records belonging to a given benthic

153 component by the total number of valid point records for all components at the permanent plot.

154 Assessing differences between methods in cover estimates

155 To assess differences between methods, we followed the approach outlined in Altman \& Bland

156 (1983) and Bland \& Altman (1986). For each site and benthic component, we subtracted the \%

157 cover estimate obtained using the CPI method from that obtained using the PQ method. We then

158 plotted these site differences against the average percent cover obtained from both methods,

159 which we considered to be the best estimate of the true percent cover value (note that the latter is

160 not known) (Altman \& Bland 1983; Bland \& Altman 1986). Such plotting allows for quick

161 visual assessment of any type of scaling relationship between the difference and the average for a

162 given benthic component at a given reef type. Such scaling relationships, if they exist, have the

163 potential to confound differences in method biases among reef types and/or benthic components

164 and thus need to be identified and accounted for.

165 In addition to plotting the differences between methods in \% cover against the average \% cover

166 for both methods at each site, we also pooled these site estimates within each reef type to

167 generate averages and 95\% confidence intervals for each reef type. The $95 \%$ confidence intervals

168 were generated via bootstrapping of site values using the "boot" package (Canty \& Ripley 2017)

169 in R (R Core Team 2017). Lack of a significant difference between methods would imply a

170 random scatter of the site difference values around the zero line, which would translate into the

171 average value for that reef type exhibiting 95\% confidence intervals largely overlapping with the

172 zero line. Similarly, the $95 \%$ confidence intervals can be used to visually compare the overall

173 differences between methods among reef types.

174 Data analysis

175 We examined each benthic component separately with a twofold aim: (1) to assess whether,

176 within a given reef type, differences in $\%$ cover scaled with the average $\%$ cover obtained from

177 both methods, and (2) to identify potential systematic differences among reef types in \% cover

178 between methods. We used an analysis of covariance (ANCOVA) framework to conduct these

179 analyses. This involved building a linear model with \% cover between methods as a response

180 variable and reef type (categorical) and the average \% cover obtained from both methods

181 (numerical covariate) as predictors, along with their interaction.

182 A statistically significant interaction between the categorical and numerical predictors would

183 imply the existence of a scaling relationship between differences in \% cover (between methods)

184 and average \% cover (of both methods) that differs in slope across reef types. This would mean

185 that the two methods translate the true abundance of a given benthic component into cover

186 estimates using functional relationships that differ fundamentally among reef types. Under such

187 scenario, accurately converting estimates between methods within and among reef types would

188 require prior knowledge of each of the different linear functional relationships for each reef type.

PeerJ reviewing PDF | (2019:07:39895:1:1:NEW 29 Oct 2019) 
189 In contrast, a lack of a significant interaction term but presence of a significant effect of average

$190 \%$ cover would imply a scaling relationship between differences in \% cover and average \% cover

191 that is similar among reef types. If there is also a significant effect of reef type, then the scaling

192 would be similar among reef types but each type would have a different baseline (intercept)

193 value. If there is not a significant reef type term, then all the reef types would share the same

194 baseline value. In the latter case, a single linear functional relationship would be required for

195 accurate conversions of method estimates within and among reef types.

196 Finally, a lack of a significant effect of average \% cover (either alone or via the interaction term)

197 would imply the absence of any scaling relationship between differences in \% cover and average

$198 \%$ cover. This would simplify conversions between methods within reef types as it would require

199 simply adding (or subtracting) a constant value to each estimate. If there is also a significant

200 effect of reef type, then such a constant would differ among reef types; if not, then the constant

201 would be the same among reef types. The latter case would be the ideal scenario because it

202 would imply the use of a single conversion constant for all estimates, irrespective of reef type.

203 Converting PQ estimates to CPI ones

204 Since our ultimate goal is to be able to meaningfully compare current and future PQ \% cover

205 estimates to historical CPI ones, we derived linear equations allowing the conversion of PQ

206 estimates to CPI ones for our data. To streamline and simplify this process, we used the previous

207 ANCOVA framework to derive the parameter estimates for the conversion equations. For each

208 benthic component, we used the most parsimonious ANCOVA model (i.e. after removing all

209 non-significant ( $\mathrm{p}>0.05)$ model terms) to obtain the relevant intercept and slope estimates for

210 each reef type. Thus, for each reef type, we obtained a simple linear model linking differences in

$211 \%$ cover between methods to average \% cover as given by Equation 1:

212 Equation 1: $\quad P Q-C P I=\beta 0+\beta 1\left(\frac{P Q+C P I}{2}\right)$,

213 where $\beta 0$ and $\beta 1$ represent the intercept and slope, respectively, of the model, and PQ and CPI

214 represent the \% cover estimates for each method.

215 Under the assumption that PQ and CPI cover estimates are indeed linearly related, then it follows

216 that Equation 1 can be re-written as Equation 2:

217 Equation 2: $\quad C P I=-\frac{\beta 0}{\left(1+\frac{\beta 1}{2}\right)}+\frac{\left(1-\frac{\beta 1}{2}\right)}{\left(1+\frac{\beta 1}{2}\right)} P Q$,

218 where the first and second fraction terms represent the intercept and slope, respectively, of the

219 linear model allowing the direct conversion of PQ estimates into CPI ones.

220 We used the "gls" function in the "nlme" package (Pinheiro et al. 2017) in R to conduct the

221 ANCOVA models. We allowed the variance components to differ among reef types in all models

222 and used residual plots to assess potential violations of necessary conditions for parametric

223 testing.

\section{Results}

225 Exploratory scatterplots assessing relationships between the \% cover estimates of both methods

226 revealed that both methods were strongly and significantly correlated across all sites for each

227 benthic component (Pearson $r \geq 0.86, n=21, p<0.001$; Fig. 3 A-F). However, a visual inspection of

228 the differences in \% cover between methods against the average \% cover of both methods 
229 revealed complex relationships that depended on both the benthic component and reef type (Fig.

2304 A-F). These patterns are summarized below by benthic component.

\section{Hard corals}

232 For hard corals, differences in \% cover between methods did not appear to scale with the average

$233 \%$ cover of both methods in any of the reef types (Fig. 4 A). Site differences in \% cover between

234 methods were consistently negative (Fig. 4 A) and, on average, appeared to differ in magnitude

235 among some reef types, as evidenced by the lack of overlap in $95 \%$ confidence intervals between

236 the bank and fringing reefs (Fig. 4 A). The ANCOVA confirmed these results; the reef type term

237 was statistically significant, but not the average cover covariate nor the interaction between the

238 latter and reef type (Table 1). Thus, for hard corals, there was no evidence that differences

239 between methods scaled significantly with average \% cover. Nevertheless, the two methods

240 differed significantly in estimates of \% cover and, importantly, the extent to which they did so

241 differed among reef types. Based on the observed average difference estimates, the PQ method

242 underestimated cover relative to the CPI method by absolute average values of $3.2 \%, 5.2 \%$ and

$2436.2 \%$ on bank, fringing and patch reefs, respectively. This allows for a straightforward

244 conversion to CPI by adding these absolute values to the PQ estimates (Table 2).

\section{Sponges}

246 For sponges, differences in \% cover between methods did not appear to scale with the average $\%$

247

248

249

250

251

252

253

254

255

256

257

258

259

260

261

262

263

264

265

266

267

270

271

272 cover of both methods in any reef type (Fig. 4 B). Most site differences in \% cover between methods were negative (13 out of 15 site values) (Fig. 4 B), and these differences did not appear to differ in magnitude among reef types, as evidenced by the overlap in $95 \%$ confidence intervals between all reef types (Fig. 4 B). This was confirmed by the ANCOVA, which indicated that the reef type term was not statistically significant, nor was the average cover covariate or the interaction between the latter and reef type (Table 1). Thus, for sponges, the two methods did not differ significantly in estimates of \% cover among reef types. However, the intercept term of the ANCOVA was significant (Table 1) indicating that the two methods still differed in their overall estimates. Pooling the observed estimates across reef types indicated that the PQ method underestimated cover relative to the CPI method by an absolute average value of $3.9 \%$ irrespective of reef type. Thus, converting PQ \% cover estimates to CPI would require adding this absolute value to the PQ estimates (Table 2).

\section{Gorgonians}

For gorgonians, differences in $\%$ cover between methods strongly scaled with the average $\%$ cover of both methods on the patch and bank reefs, and they did so in a manner that appeared consistent between these two reef types (Fig. 4 C). In contrast, site differences on the fringing reefs, which showed very low values for the averages between methods, revolved closely around the zero line (Fig. 4 C). On average, and taken at face value, differences between methods scaled with average $\%$ cover across reef types and the lack of overlap in $95 \%$ confidence intervals supported that reef differences were statistically significant (Fig. 4 C). The ANCOVA showed a highly significant effect of both the reef type and the gorgonian average abundance covariate (Table 1). However, the interaction term was not significant, indicating a consistent scaling relationship across reef types (Table 1). Thus, for gorgonians, differences between methods scaled significantly (and positively) with average \% cover in a manner that was consistent among reef types. Nevertheless, the baseline values (intercepts) differed significantly among reef types. In summary, accurately converting PQ \% cover values to CPI would require a linear 
273 transformation with the same slope but different baseline values among reef types (Table 2).

274 However, assessment of the residual plots for this benthic group indicated some evidence of

275 heterogeneity of variance (despite the use of different variance components for each reef type).

276 This warrants extra caution in the interpretation of the significance of some of the model terms,

277 although it is unlikely that this would affect the visually obvious scaling relationship with

278 average \% cover (Fig. 4 C).

279 Macroalgae

280 For macroalgae, differences in \% cover between methods appeared to scale negatively with the

281 average \% cover of both methods in most reef types (Fig. 4 D). Most site differences in \% cover

282 between methods were negative (12 out 15 site values) (Fig. 4 D). On average, and taken at face

283 value, these differences appeared to differ in magnitude among some reef types, as evidenced by

284 the lack of overlap in 95\% confidence intervals between patch and fringing reefs (Fig. 4 D). The

285 ANCOVA confirmed the significant effect of both reef type and the average \% cover covariate,

286 but failed to find a significant effect of the interaction between the two (Table 1). Thus, for

287 macroalgae, differences between methods scaled significantly (and negatively) with average \%

288 cover in a manner that was consistent among reef types. Nevertheless, the baseline values

289 (intercepts) differed significantly among reef types. Thus, accurately converting PQ \% cover to

290 CPI would require a linear transformation with the same slope but different baseline values

291 among reef types (Table 2).

292 Turfalgae

293 For turf algae, differences in \% cover between methods scaled strongly with the average \% cover

294 of both methods in a way that differed among reef types (Fig. 4 E). For example, whereas site

295 differences in \% cover between methods appeared to increase with average cover on both

296 fringing and patch reefs, they appeared to decrease on bank reefs (Fig. 4 E). On average, and

297 taken at face value, differences between methods appeared to differ in magnitude among reef

298 types, as evidenced by the minimum overlap in $95 \%$ confidence intervals between the patch and

299 fringing reefs (Fig. 4 E). The ANCOVA confirmed the presence of a highly significant

300 interaction term between average \% cover and reef type; reef type (but not the average cover

301 covariate) was also statistically significant (Table 1). Thus, the magnitude of the differences

302 between methods scaled significantly with average \% cover in a way that differed among reef

303 types, precluding straightforward overall comparisons within and among reef types. In summary,

304 accurately converting PQ \% cover to CPI would require a linear transformation with different

305 slopes and different baseline values among reef types (Table 2).

306 Crustose coralline algae (CCA)

307 For CCA, differences in \% cover between methods scaled with the average \% cover of both

308 methods in some reef types (e.g. bank reefs) but not others (e.g. patch reefs) (Fig. 4 F).

309 Moreover, site differences in \% cover between methods were relatively small in patch and

310 fringing reefs, but large (and mainly positive) on the bank reefs (Fig. 4 F). On average, and taken

311 at face value, these differences appeared to differ in magnitude among reef types, as evidenced

312 by the lack of overlap in $95 \%$ confidence intervals between the bank reefs and the other two reef

313 types (Fig. 4 F). The ANCOVA revealed that the interaction term between average \% cover and

314 reef type was significant, as were all the other terms in the model (Table 1). Thus, the magnitude

315 of the differences between methods scaled significantly with average $\%$ cover in a way that

316 differed among reef types, precluding straightforward comparisons within and among reef types. 
317 In summary, accurately converting PQ \% cover to CPI would require a linear transformation

318 with different slopes and different baseline values among reef types (Table 2).

319 Table 2 provides a summary of our main findings for each benthic component and the linear 320 functions to convert PQ \% cover estimates to CPI ones for each reef type using Equation 2 (see 321 Fig. S1 A-F for a graphic display of these conversions for each benthic component). Replacing the original PQ values with these converted ones removes all visual evidence of systematic biases and scaling relationships between methods, as expected (see Fig. S2 A-F).

\section{Discussion}

We have demonstrated statistically significant differences in estimates of $\%$ cover between the PQ and CPI method at our reefs for the most commonly used benthic components in coral reef monitoring programs. Importantly, we have shown that the magnitude and nature of such differences depends variously on the benthic component of interest, the abundance (\% cover) of that component, and the type of reef examined.

330 Beyond showing that differences between methods are complex and statistically significant, we further argue that the magnitude of these method biases is important from a management perspective and should not be ignored. We illustrate this point by using additional CPI data from the Barbados Reef Monitoring Programme to assess changes in hard coral \% cover between 2012 and 2017 at the same 21 study sites. Comparing the 2012 estimates with those of 2017 obtained using the same CPI methodology reveals a statistically significant (albeit small) overall increase in absolute \% cover across all reef types (Fig. 5 A). In contrast, comparing the 2012 CPI estimates with the original 2017 PQ ones reveals the opposite pattern, i.e. a small yet statistically significant overall decrease in hard coral absolute \% cover (Fig. 5 B). The true trend is recovered once the PQ data are converted to CPI estimates (Fig. 5 C). Clearly, switching to PQ data without adequately accounting for method differences would have obscured this modest, yet optimistic, signal and led to an erroneous conclusion about recent trends in coral cover in Barbados by masking the upward trend in coral cover and suggesting a decline instead.

343 Thus, our study shows that (1) \% cover estimates obtained using the PQ method will need to be converted to allow for meaningful comparisons with historical data obtained using the CPI method in Barbados and (2) the nature of this conversion will differ depending on the benthic component of interest and the type of reef examined (Table 2).

What drives this complex pattern of differences between methods in cover estimates? Following Leujak \& Ormond (2007), we consider a number of potentially interacting factors, namely (1) the contour effect, (2) the proportion of substrate sampled, (3) the angle of view, (4) image resolution, (5) observer bias, and (6) data calculation.

The contour effect results from the fact that the PQ method samples the benthos through a 2D horizontal plane (bird's-eye view) and as such it will systematically ignore information about the vertical contour (rugosity) of the benthos, whereas the CPI method purposely samples along that vertical contour (Hill \& Wilkinson 2004; Rogers et al. 1994). This implies that benthic features exhibiting a pronounced vertical dimension will likely be underestimated by the PQ relative to the CPI method. This might explain why the PQ method yielded consistently lower cover estimates for hard corals and sponges than the CPI method across all reef types in our study, as these are the benthic components typically responsible for most of the vertical structure on coral reefs. Interestingly, and in contrast to our findings, Rogers (1999) and Rogers \& Miller (2001), 
360 who compared video images with the chain intercept transect method in what are likely the most

361

362

363

364

365

366

367

368

369

370

371

372

373

374

375

376

377

378

379

380

381

382

383

384

385

386

387

388

389

390

391

392

393

394

395

396

397

398

399

400

401

402

403

404

405 comparable studies to ours, found no differences in coral cover between methods. Since objects close to the camera will appear larger than those of the same size but further away from the camera (Porter \& Meier 1992), this might have partially counterbalanced the contour effect in their studies, suggesting that the overall physical structure of the reef, as well as the height of the camera above the substrate (e.g. only $\sim 40 \mathrm{~cm}$ in Roger \& Miller's study versus $\sim 100 \mathrm{~cm}$ in ours), are important. Furthermore, the fact that differences between methods in coral cover estimates varied in magnitude across reef types is not surprising. Several authors have reported sitespecific differences in method biases, attributing these to differences in spatial heterogeneity (Dodge et al. 1982), physical complexity (Nadon \& Stirling 2005) or coral cover (Lam et al. 2006).

Another important factor is the considerable difference between methods in the proportion of benthic substrate that was effectively sampled within the permanent plot. Although we ensured that the number of sample points used within each plot was roughly similar between methods, the effective area sampled differed by one order of magnitude. The PQ method employed here involved sampling points distributed across $660.54 \mathrm{~m}^{2}$ quadrats, representing a total sampled area of $35.6 \mathrm{~m}^{2}(17.8 \%)$ out of the $200 \mathrm{~m}^{2}$. In contrast, the CPI method involved sampling points distributed along ten chains averaging $\sim 13 \mathrm{~m}$ in length (depending on the reef contour) and just $0.005 \mathrm{~m}$ wide, representing a total sampled area of little more than $0.65 \mathrm{~m}^{2}(0.33 \%)$. This is an intrinsic limitation of all line transect methods and the consequence is that, everything else being equal, they are more likely to underestimate the least abundant benthic components (Leujak \& Ormond 2007). Thus, the PQ method should provide more representative estimates of benthic cover at low abundance, particularly in the inherently heterogeneous benthos of most coral reefs. In our study, such an effect should have translated into higher PQ estimates when average abundance (\% cover) of the benthic component was low, if the rarer benthic components were systematically missed by the CPI method. Yet, this was generally not the case (Fig. 4 A-F), suggesting that the difference in effective area sampled was not an important factor. The pooling of data into the six broad benthic components might have contributed to reduce its influence, but this factor might become important when individual taxa are examined separately (Leujak \& Ormond 2007) or if some of the broad benthic components (e.g. hard corals which currently average $20.4 \%$ cover across the study sites) were to decrease considerably in overall abundance in the future.

Leujak \& Ormond (2007) also highlight variability in the angle of view (parallax error) as a potentially important factor leading to differences in estimates between methods. This factor was minimized in the PQ method by using a monopod, which was consistently placed perpendicular to the main plane of the substrate. In contrast, this factor could have been particularly problematic if the chain used by the CPI method to sample the benthic component had been maintained taut between the transect ends with minimum physical contact with the substrate itself. Under such conditions, small changes in the observer's angle of view would have affected what benthic component was perceived to be directly perpendicular to the sampling chain; as a consequence, the most dominant benthic components would have likely been overrepresented. This effect would be further exacerbated under sea conditions (swells or currents) that can shift the position of the suspended line. However, because the CPI method uses a non-buoyant chain that is draped along the substrate contour (rather than kept taut away from the substrate), viewing angle artefacts are likely to have been small (but not impossible, particularly in instances where the chain overhangs vertically, or under strong swells) compared to line transect methods where 
406

407

408

409

410

411

412

413

414

415

416

417

418

419

420

421

422

423

424

425

426

427

428

429

430

431

432

433

434

435

436

437

438

439

440

441

442

443

444

445

446

447

448

449

the overhanging line is kept taut (Dodge et al. 1982). Furthermore, because multiple chains were laid within the same permanent plot, the potential effects of parallax and chain shifts would have been more likely to be averaged out at the scale of the entire plot. Thus, overall, we suspect that this factor was not highly influential in our study.

Image resolution of underwater digital cameras has been a major constraint in the development of photoquadrat and video methods for benthic coral reef monitoring (Brown et al. 2004; Carleton \& Done 1995; Lam et al. 2006; Ninio et al. 2003; Preskitt et al. 2004). However, photographic technology is improving rapidly and so we were able to consistently obtain image resolution of appropriately high quality for most benthic groups throughout our study. For example, our identification of hard coral species using PQ, agreed closely with our in-situ coral identification using the CPI method (Henderson 2017), supporting high accuracy in distinguishing between hard coral and other benthic components. However, this was not always the case for some small sponges and macroalgae patches captured by the CPI, which might have been occasionally misidentified as other benthic components in the PQ method due to insufficient resolution.

Overall, the biggest PQ image processing challenge we faced was distinguishing between a mixture of CCA, macroalgae, and sometimes turf algae on the bank reefs because of the dimmer images that result from greater depths, a common problem in these types of studies (e.g. Rogers 1999; Rogers \& Miller 2001). It is therefore possible that the consistently higher CCA values obtained using the PQ method on the bank reefs relative to the CPI method might partially reflect an incorrect systematic attribution of sampling points to CCA in lieu of macroalgae and/or turf algae cover. In spite of this, we found our PQ method to be generally satisfactory in the context of the broad benthic components that were of interest in this study, in line with other studies (Aronson et al. 1994; Ninio et al. 2003). Obviously, the level of image resolution needed will be dictated by the level of taxonomic resolution of interest and in that regard we found that identifying some small macroalgae and small sponges to species level was often difficult. Likewise, the flexibility of using multiple cues for in-situ identification offered by the CPI method cannot be sufficiently overstated. This issue should be carefully borne in mind if one of the ultimate purposes of the PQ method is to provide photographic records of the benthic communities for potential use in ways that go beyond simple monitoring. Supplementing PQ with in situ notes for the rarer and more cryptic taxa seems a promising approach to circumvent some of the identification problems (Preskitt et al. 2004).

Although we recognize the potentially important role that observer bias can play when collecting benthic data, we believe that this was not an important factor in generating differences between methods in our study. Using a chain draped over the substrate minimized any potential bias associated with identifying the substrate directly beneath the chain, which is a problem when the line is taut and suspended above the substrate (Leujak \& Ormond 2007). Taxonomic identification of reef benthic organisms can be quite challenging, particularly when these are small-sized and rare (Ohlhorst et al. 1988). However, the use of broad benthic categories by our study meant that most of the sessile organisms recorded in situ (CPI) and with sufficient resolution in the images (PQ) could be allocated to the appropriate category by any observer after minimum training. This is in line with inter-observer variability assessments of taxa identification in the field (e.g. Nadon \& Stirling 2005) and from photographic images (e.g. Ninio et al. 2003). 
450 How the \% benthic cover estimates are derived from the raw data is another factor potentially 451 leading to differences in estimates between methods. In both methods, calculation of \% benthic 452 cover involved dividing the total number of records belonging to a given benthic component by the total number of records for all components within the permanent plot. This necessarily implies some degree of dependency between cover estimates of the different benthic components since their sum should be equal to $100 \%$. By extension, summing the $\%$ cover differences 456 between methods across all benthic components should yield a value of $0 \%$. This implies that large negative differences between methods for some benthic components will necessarily artificially lead to large positive differences for other benthic components, and thus to an apparent over-representation for the latter. Thus, at the reef type level, the consistently higher estimates of turf algae on the fringing and patch reefs and of CCA on the bank reefs obtained by the PQ method (Fig. 4 E-F) are, to some degree, a likely artefact of the consistently lower estimates for corals and sponges, obtained by this method (Fig. 4 A-B). In any case, this point highlights the problem of interpretation of \% cover values particularly when data are obtained using planar view approaches as these cannot track associations between the substrate contour and the different benthic components. Thus, although we agree with Leujak \& Ormond (2007)'s assertion that two-dimensional planar projections as derived by photographic methods provide a standardised measure of substrate cover that is independent of reef physical complexity, the latter ceases to be the case once the raw data are transformed into percentages, which is the general rule.

Beyond Leujak \& Ormond (2007)'s six aforementioned factors, we also detected a very strong "gorgonian effect" whereby differences between methods in gorgonian cover estimates increased in magnitude with overall gorgonian abundance. This effect resulted from the two methods interacting quite differently with the morphological features of gorgonians. The CPI method sampled the relatively small horizontal surface area of the gorgonian holdfasts. In contrast, the photographs of the PQ method were often dominated by the larger fan- and tree-like vertical bodies of the individual gorgonians, in spite of the camera's top-down view, ultimately yielding PQ estimates that scaled with gorgonian abundance at a greater rate than in the CPI method (Fig. $4 \mathrm{C}$ ). This phenomenon was often exacerbated by currents and swells pushing gorgonians into the frame of the photo and adding an additional source of method bias. For the same reasons, Rogers (1999) and Rogers \& Miller (2001) also found that estimates of gorgonian cover using video were consistently higher than those obtained using a chain method. Furthermore, revisiting their data shows that differences between methods also scaled with average gorgonian abundance, suggesting that this is a common phenomenon, although this specific aspect was not explicitly investigated by these authors. Furthermore, unlike CCA and turf algae, the scaling relationship for gorgonians was similar among reef types, which likely reflects an overriding effect of the interaction between the peculiar gorgonian morphology and their inclusion in the photo images. Having said that, this peculiar morphology implies that their abundance is likely better assessed using approaches that do not rely on \% benthic cover estimates such as colony counts on belt transects (Rogers et al. 1994). However, where gorgonians are quite abundant and

490 the PQ method is still used to assess the other benthic components, field and lab protocols should be put in place to minimize gorgonian overrepresentation on the PQ images.

492 We detected statistically significant differences between methods in cover estimates for all benthic components examined. We believe the analytical framework used here (Altman \& Bland 
496 between methods tend to use statistical approaches that would have ignored the scaling

497 relationships identified in our study for most benthic components (e.g. ANOVAs and t-tests and

498 their non-parametric analogues) (Beenaerts \& Vanden Berghe 2005; Carleton \& Done 1995;

499 Dodge et al. 1982; Jokiel et al. 2015; Weinberg 1981). When such scaling relationships exist, not

500 accounting for them will result in higher unexplained variance and consequently in lower power

501 to detect method-specific effects. In that line, a lack of significant differences between methods

502 is often interpreted as methods being comparable, yet few studies actually address the issue of

503 statistical power during such comparisons (but see Carleton \& Done 1995; Long et al. 2004).

504 Data transformation might help in some cases but such approach misses out on an opportunity to

505 better understand what drives these differences. We also concur with Bland \& Altman (1986) in

506 that the use of correlations between method estimates (e.g. Bouchon 1981; Wilson et al. 2007) is

507 neither technically suitable nor informative enough if the specific goal is to assess whether data

508 from different methods can be used interchangeably. The latter is best exemplified by Beenaerts

$509 \&$ Vanden Berghe (2005), who found \% coral cover estimates between methods to be highly

510 correlated, in line with our own findings (Fig. 3 A-F), yet their methods also significantly

511 differed in their absolute estimates of \% coral cover. Clearer statistical and biological criteria are

512 therefore needed to guide such method comparisons.

513 Finally, to streamline and simplify the process of generating functions to convert PQ \% cover

514 estimates to CPI ones, we have here made use of the already existing ANCOVA statistical

515 framework and outputs to (indirectly) derive the parameter estimates for the conversion functions

516 (Equation 2). An alternative to this approach is to conduct major axis (MA) regression (a type of

517 Model II regression) (Legendre \& Legendre 2012) using CPI and PQ directly as response and

518 independent variables, respectively, for each reef type where relevant. Under a MA regression

519 framework, both variables (CPI and PQ) are assumed to be subject to similar random sampling

520 errors, which in this case is a reasonable expectation; MA regression will yield slopes that are

521 symmetrical between methods (Legendre \& Legendre 2012). In contrast, the ANCOVA

522 framework assumes that the independent variable (i.e. average percent cover between methods)

523 is measured with negligible sampling error, an unlikely scenario in many biological studies

524 (Quinn \& Keough 2002) and in our specific context. Although this will not affect conclusions

525 about the existence of statistically significant scaling relationships, it might ultimately lead to an

526 under- or over-estimation of their slope parameters (Quinn \& Keough 2002). On the other hand,

527 the ANCOVA framework has the practical advantage of readily allowing for the integration of

528 different variance components and for data pooling across reef types, when appropriate. We are

529 not aware of any publicly available software that integrates both approaches. Since both

530 approaches make different assumptions about sampling error and use the available data in

531 different forms, they will generally result in different slope parameter estimates (and by

532 extension, in different intercepts). In our case, and for those benthic components that exhibited

533

534

535

536

537

538 scaling relationships, which approach is ultimately used to subsequently derive the model parameters made little difference to our converted PQ \% cover estimates (Table S3). However, how these different approaches perform on datasets independently obtained from the ones that were used to develop the conversion models (i.e. model validation) still remains to be seen and highlights an important area for future research that could include both empirical and simulation studies. 


\section{Conclusion}

540 In conclusion, any attempt to transition between chain intercept transect methods and

541 photoquadrat methods will require describing the nature of the differences between methods,

542 which is very likely to depend on both the benthic components of interest as well as the reef

543 type. We suspect that this conclusion is likely to also apply to comparisons involving benthic

544 methods other than the ones specifically examined in this study. It is recommended that the

545 transition period involves surveying as many permanent sites (or sites of special interest) as

546 possible using both methods so as to quantify as accurately as possible the varying nature of

547 those relationships. Indeed, in this study we only had seven sites per reef type and it is possible

548 that some of our analyses might have suffered from low power to detect more subtle differences.

549 Importantly, future work should examine in more detail the practical, empirical and theoretical

550 merits of different between-method conversion procedures, which was beyond the scope of our

551 study. Finally, we believe that an analytical framework like the one presented in this paper can

552 guide and help standardize the process of comparing reef survey methods, even beyond the

553 context of benthic monitoring programs.

\section{Acknowledgements}

555 We acknowledge the Coastal Zone Management Unit of the Government of Barbados for use of 556 the 2012 and 2017 CPI data from the Barbados Reef Monitoring Programme (BRMP). We also 557 acknowledge the significant contributions of survey divers Renata Goodridge, Amy Cox, 558 Annabel Cox and Julian Walcott; and data processing and management by Annabel Cox and 559 Amy Cox.

\section{References}

561 Alcolado PM, Alleng G, Bonair K, Bone D, Buchan K, Bush PG, De Meyer K, Garcia JR, Garzon-Ferreira J, Gayle PMH, Gerace DT, Geraldes FX, Jordan-Dahlgren E, Kjferve B, Klein E, Koltes K, Laydoo RS, Linton DM, Ogden JC, Oxenford HA, Parker C, Penchaszadeh P, Pors LPPJ, Ramirez-Ramirez J, Ruiz-Renteria F, Ryan JD, Smith SR, Tschirky J, Varela R, Walker S, Weil E, Wiebe WJ, Woodley JD, Zieman JC, and Caricomp. 2001. The Caribbean coastal marine productivity program (CARICOMP). Bulletin of Marine Science 69:819-829.

565

566

567

568

Allard P. 1994. Changes in coral community structure in Barbados : effects of eutrophication and reduced grazing pressure MSc. McGill University.

Altman DG, and Bland JM. 1983. Measurement in Medicine: the Analysis of Method Comparison Studies. The Statistician 32:307-317.

Aronson RB, Edmunds PJ, Precht WF, Swanson DW, and Levitan DR. 1994. Large-scale, long-term monitoring of Caribbean coral reefs: Simple, quick, inexpensive techniques. Atoll Research Bulletin 421:1-19.

Beenaerts N, and Vanden Berghe E. 2005. Comparative Study of Three Transect Methods to Assess Coral Cover, Richness and Diversity. West Indian Journal of Marine Science 4:29-37.

Bland JM, and Altman DG. 1986. Statistical methods for assessing agreement between two methods of clinical measurement. The Lancet 327:307-310.

Bouchon C. 1981. Quantitative Study of the Scleractinian Coral Communities of a Fringing Reef of Reunion Island (Indian Ocean). Marine Ecology Progress Series 4:273-288.

Brathwaite A, Oxenford HA, and Roach R. 2018. Barbados: a coral paradise: Miller Publishing. 
581

582

583

584

585

586

587

588

589

590

591

592

593

594

595

596

597

598

599

600

601

602

603

604

605

606

607

608

609

610

611

612

613

614

615

616

617

618

619

620

621

622

623

624

625

626

627

628
Brown E, Cox E, Jokiel P, Rodgers K, Smith W, Tissot B, Coles SL, and Hultquist J. 2004. Development of Benthic Sampling Methods for the Coral Reef Assessment and Monitoring Program (CRAMP) in Hawai'i. Pacific Science 58:145-158.

Burke L, and Maidens J. 2004. Reefs at Risk in the Caribbean. Washingon, DC: World Resource Institute. Canty A, and Ripley B. 2017. boot: Bootstrap R (S-Plus) Functions. R package version 1.3-20.

Carleton JH, and Done TJ. 1995. Quantitative video sampling of coral reef benthos: large-scale application. Coral Reefs 14:35-46.

CERMES. 2018. The Barbados Coral Reef Monitoring Programme: Changes in coral reef communities on the west and south coasts 2007-2017. Report for the Coastal Zone Management Unit, Government of Barbados. $p$ 81.

Cortés J, Oxenford HA, van Tussenbroek BI, Jordán-Dahlgren E, Cróquer A, Bastidas C, and Ogden JC. 2019. The CARICOMP Network of Caribbean Marine Laboratories (1985-2007): History, Key Findings, and Lessons Learned. Frontiers in Marine Science 5.

Dodge RE, Logan A, and Antonius A. 1982. Quantitative Reef Assessment Studies in Bermuda: A Comparison of Methods and Preliminary Results. Bullentin of Marine Science 32:745-760.

Ferreira CEL, Goncalves JEA, and Coutinho R. 2001. Community structure of fishes and habitat complexity on a tropical rocky shore. Environmental Biology of Fishes 61:353-369.

Flower J, Ortiz JC, Chollett I, Abdullah S, Castro-Sanguino C, Hock K, Lam V, and Mumby PJ. 2017. Interpreting coral reef monitoring data: A guide for improved management decisions. Ecological Indicators 72:848-869.

GCRMN-Caribbean. 2016. GCRMN-Caribbean guidelines for coral reef biophysical monitoring. UNEP(DEPI)/CAR WG.38/INF.17

Green RH, and Smith SR. 1997. Sample program design and environmental impact assessment on coral reefs. In: Lessios HA, and Macintyre IG, eds. Proceedings of the 8th International Coral Reef Symposium Vol 2 Smithsonian Tropical Research Institute, Panama 1459-1464.

Henderson A. 2017. Comparison of photoquadrat and linear point-intercept methods to assess benthic cover on coral reefs. MSc Research Paper, University of the West Indies, Cave Hill, 48 pp.

Hill J, and Wilkinson C. 2004. Methods for ecological monitoring of coral reefsa resource for managers. Townsville: Australian Institute of Marine Science (AIMS).

Hodgson G, Hill J, Kiene W, Maun L, Mihaly J, Liebeler J, Shuman C, and Torres R. 2006. Reef Check Instruction Manual: A Guide to Reef Check Coral Reef Monitoring. Pacific Palisades, California, USA: Reef Check Foundation

Houk P, and Van Woesik R. 2006. Coral Reef Benthic Video Surveys Facilitate Long-Term Monitoring in the Commonwealth of the Northern Mariana Islands: Toward an Optimal Sampling Strategy. Pacific Science 60:177-189.

Jackson JBC, Donovan MK, Cramer KL, and Lam W. 2014. Status and trends of Caribbean coral reefs: 1970-2012. Gland, Switzerland: Global Coral Reef Monitoring Network, IUCN. p 306 pp.

Jokiel PL, Rodgers KS, Brown EK, Kenyon JC, Aeby G, Smith WR, and Farrell F. 2015. Comparison of methods used to estimate coral cover in the Hawaiian Islands. PeerJ 3:e954.

Kholer K, and Gill SM. 2006. Coral Point Count With Excel Extensions (CPCe): A Visual Basic Program For The Determination Of Coral And Substrate Coverage Using Random Point Count Methodology. Computers and Geosciences 32:1259-1269.

Lam K, Shin PKS, Bradbeer R, Randall D, Ku KKK, Hodgson P, and Cheung SG. 2006. A comparison of video and point intercept transect methods for monitoring subtropical coral communities. Journal of Experimental Marine Biology and Ecology 333:115-128.

Lang JC, Marks KW, Kramer PR, and Ginsburg RN. 2010. AGRRA Protocols Version 5.4 [WWW Document].

Legendre P, and Legendre L. 2012. Numerical Ecology. Amsterdam, The Netherlands: Elsevier. 
629

630

631

632

633

634

635

636

637

638

639

640

641

642

643

644

645

646

647

648

649

650

651

652

653

654

655

656

657

658

659

660

661

662

663

664

665

666

667

668

669

670

671

672

673

674
Leonard GH, and Clark RP. 1993. Point Quadrat Versus Video Transect Estimates of the Cover of Benthic Red Algae. Marine Ecology Progress Series 101:203-208.

Leujak W, and Ormond RFG. 2007. Comparative accuracy and efficiency of six coral community survey methods. Journal of Experimental Marine Biology and Ecology 351:168-187.

Lindeman KC, Kramer PA, and Ault JS. 2001. Comparative approaches to reef monitoring and assessment: An overview. Bulletin of Marine Science 69:335-338.

Long BG, Andrews G, Wang Y-G, and Suharsono. 2004. Sampling accuracy of reef resource inventory technique. Coral Reefs 23:378-385.

Mumby PJ, Flower J, Chollett I, Box SJ, Bozec Y-M, Fitzsimons C, Forster J, Gill D, Griffith-Mumby R, Oxenford HA, Townsley P, van Beukering PJH, Booker F, Brocke HJ, Cabañillas-Terán N, Canty SWJ, Carricart-Ganivet JP, Charlerly J, Dryden C, van Duyl FC, Enríquez S, den Haan J, IglesiasPrieto R, Kennedy EV, Mahon R, Mueller B, Newman SP, Nugues MM, Cortés Núñez J, Nurse L, Osinga R, Paris CB, Petersen D, Polunin NVC, Sánchez C, Schep S, Stevens JR, Vallès H, Vermeij MJA, Visser PM, Whittinghan E, and Williams SM. 2014. Towards Reef Resilience and Sustainable Livelihoods: A handbook for Caribbean coral reef managers. Exeter: University of Exeter.

Mumby PJ, and Steneck RS. 2008. Coral reef management and conservation in light of rapidly evolving ecological paradigms. Trends in Ecology \& Evolution 23:555-563.

Nadon M-O, and Stirling G. 2005. Field and simulation analyses of visual methods for sampling coral cover. Coral Reefs 25:177-185.

Ninio R, Delean S, Osborne K, and Sweatman H. 2003. Estimating cover of benthic organisms from underwater video images: variability associatedwith multiple observers. Marine Ecology Progress Series 265:107-116.

Ohlhorst SL, Liddell WD, Taylor RJ, and Taylor JM. 1988. Evaluation of reef census techniques. Proceedings of the 6th International Coral Reef Symposium, Australia 2:319-324.

Oxenford HA, Roach R, Brathwaite A, Nurse L, Goodridge R, Hinds F, Baldwin K, and Finney C. 2008. Quantitative observations of a major coral bleaching event in Barbados, Southeastern Caribbean. Climatic Change 87:435-449.

Pinheiro J, Bates D, DebRoy S, Sarkar D, and Team RC. 2017. nlme: Linear and Nonlinear Mixed Effects Models. $R$ package version 3.1-131. https://CRAN.R-project.org/package=nlme $>$.

Porter JW, and Meier OW. 1992. Quantification of Loss and Change in Floridian Reef Coral Populations. Integr Comp Biol 32:625-640.

Preskitt LB, Vroom PS, and Smith CM. 2004. A Rapid Ecological Assessment (REA) Quantitative Survey Method for Benthic Algae Using Photoquadrats with Scuba. Pacific Science 58:201-209.

Quinn GP, and Keough MJ. 2002. Experimental design and data analysis for biologists. Cambridge, U.K.: Cambridge University Press.

R Core Team. 2017. R: A language and environment for statistical computing. R Foundation for Statistical Computing, Vienna, Austria. URL https://www.R-project.org/.

Rogers CS. 1998. Sampling may be haphazardous to your reef monitoring program. Proceedings of the Hawaii Coral Reef Monitoring Workshop June 11-19 Honolulu, Hawai:57-64.

Rogers CS. 1999. Sampling May be Haphazardous to Your Reef Monitoring Program. In: Maragos JE, and Grober-Dunsmore R, eds. Proceedings of the Hawaii Coral Reef Monitoring Workshop June 9-11 Honolulu, Hawai.

Rogers CS, Gilnack M, and Fitz HC. 1983. Monitoring of Coral Reefs with Linear Transects - a Study of Storm Damage. Journal of Experimental Marine Biology and Ecology 66:285-300.

Rogers CS, Ginger G, Grober R, Hillis Z-M, and Franke MA. 1994. Coral Reef Monitoring Manual for the Caribbean and Western Atlantic. National Park Service. Virgin Islands National Park. p 114.

Peer) reviewing PDF | (2019:07:39895:1:1:NEW 29 Oct 2019) 
675 Rogers CS, and Miller J. 2001. Coral bleaching, hurricane damage, and benthic cover on coral reefs in St.

676

677

678

679

680

681

682

683

684 John, U.S. Virgin Islands: A comparison of surveys with the chain transect method and videography. Bullentin of Marine Science 69:459-470.

Vallès $\mathrm{H}$, Trew H, Oxenford HA, Goodridge R, and Hunte W. 2019. Spatio-temporal variability in the benthic composition of the coral reefs of Barbados between 1997 and 2012. Proceedings of the Gulf and Caribbean Fisheries Institute 71:82-84.

Weinberg S. 1981. A comparison of coral reef survey methods. Bijdragen Tot De Dierkunde 51:199-218. Wilson SK, Graham NAJ, and Polunin NVC. 2007. Appraisal of visual assessments of habitat complexity and benthic composition on coral reefs. Marine Biology 151:1069-1076. 


\section{Figure 1}

Map of Barbados showing locations of the 21 reef survey sites along the west and southwest coasts.

Inset map (A) shows position of Barbados in the southeastern Caribbean. Photographs show typical reef types in Barbados - (B) fringing reef, (C) patch reef, and (D) bank reef.

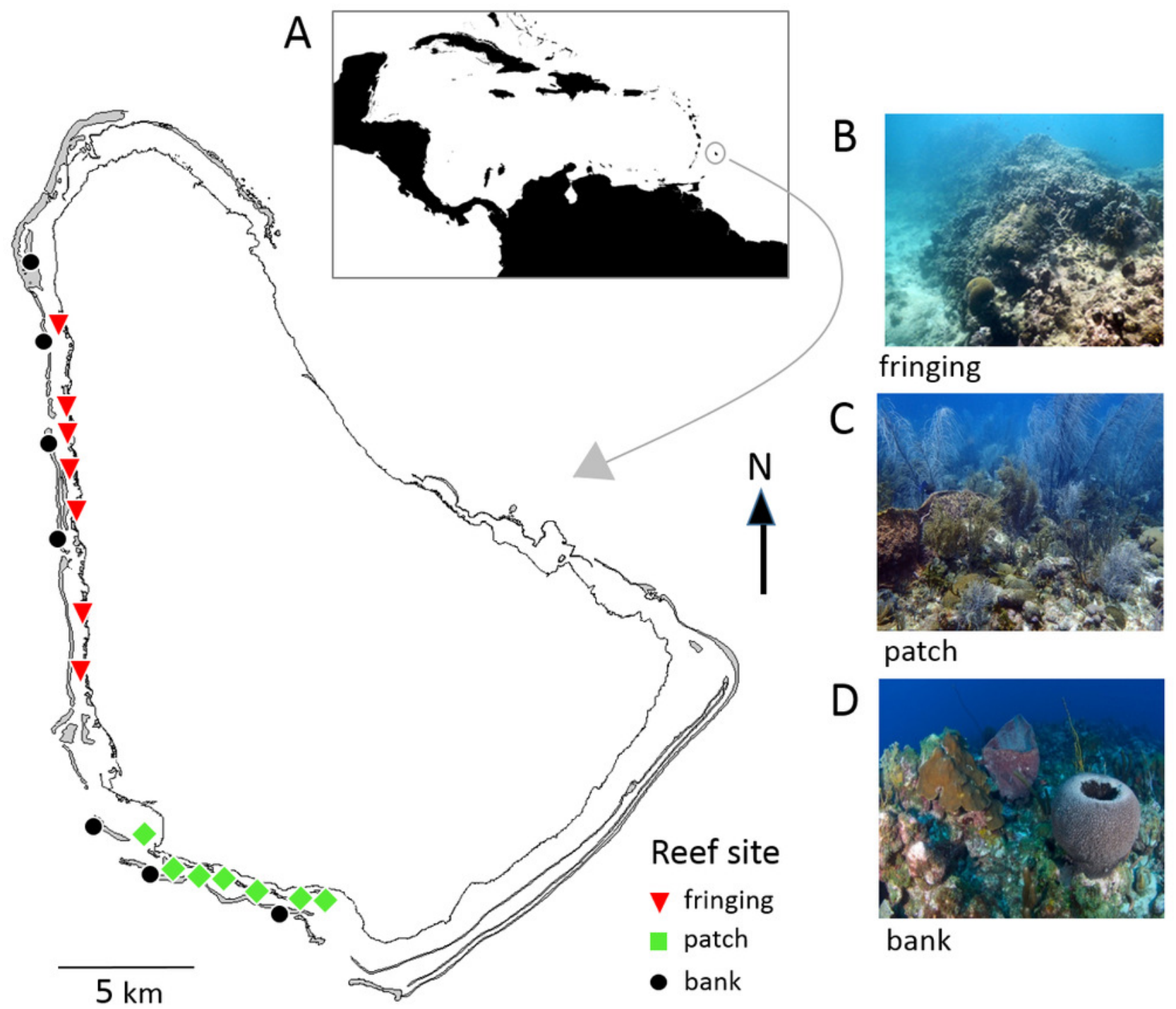


Figure 2

Layout of $10 \times 20$ m permanent monitoring plot showing permanent corner marks, $(A)$ positions of 10 temporary chain transects and (B) positions 11 temporary transects with 66 photoquadrats.

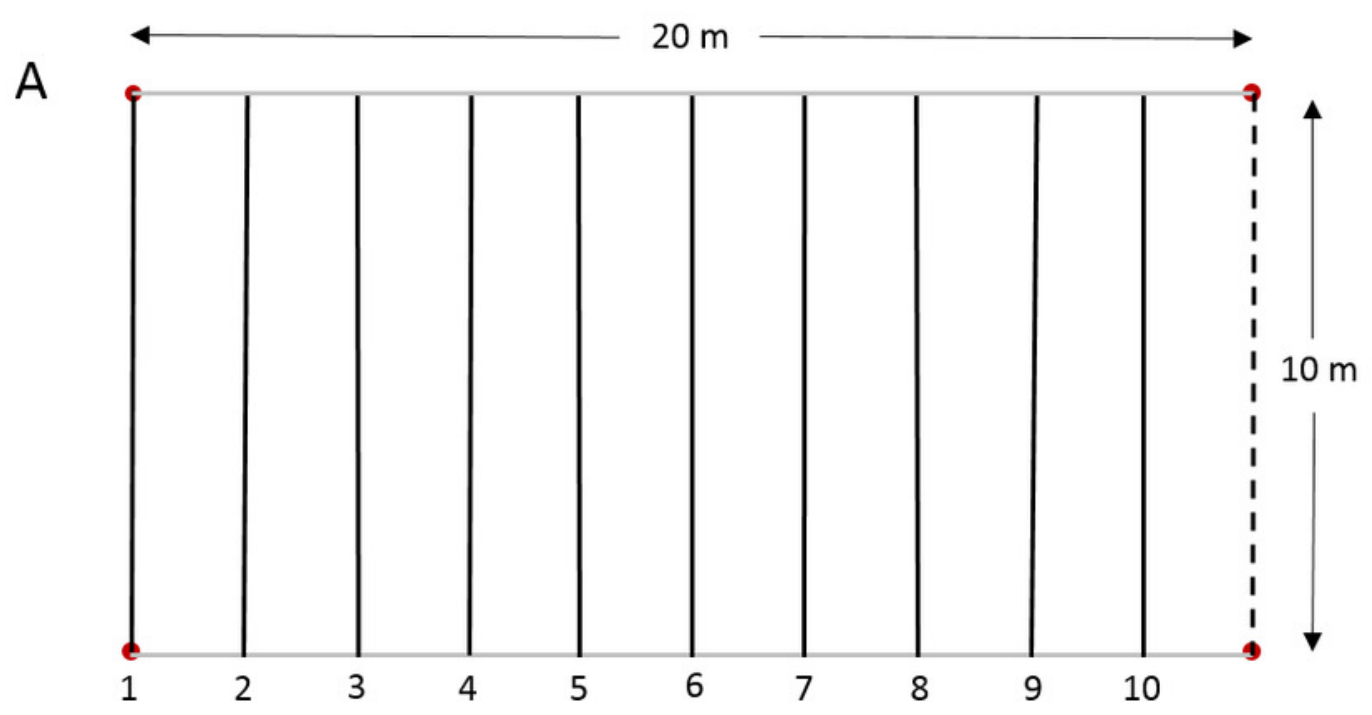

B

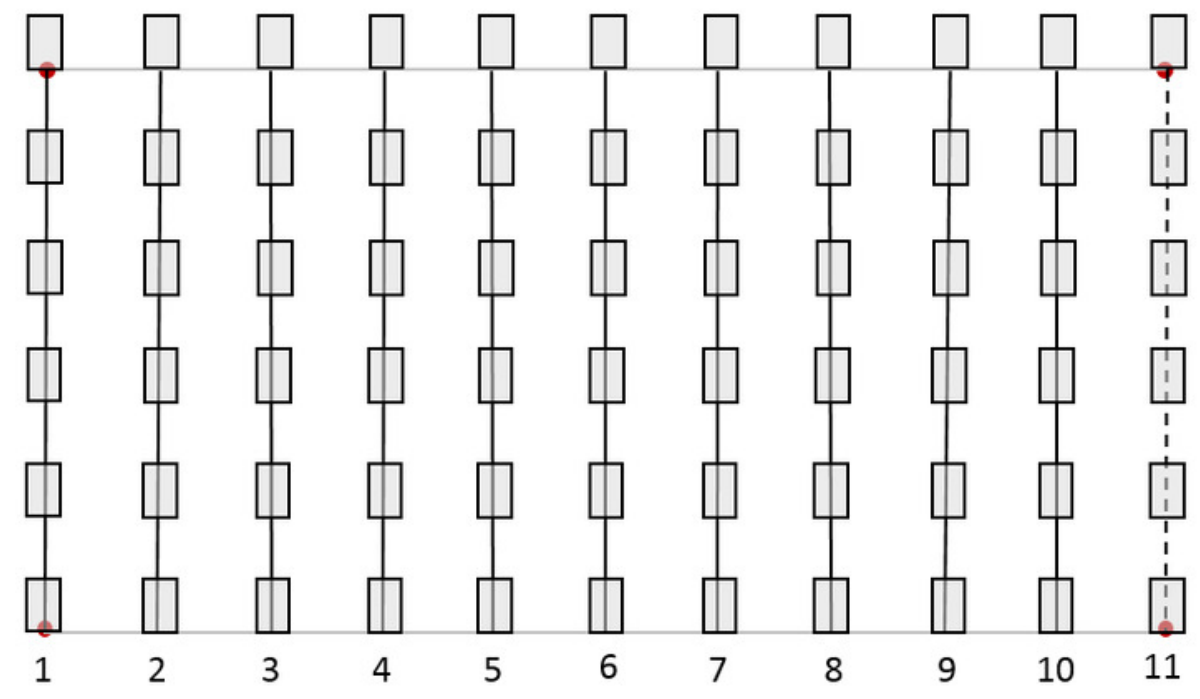

- chain transect photoquadrat

1 transect no.

- permanent mark 
Figure 3

Scatterplots showing original percent cover values obtained using the chain pointintercept (CPI) method versus the photoquadrat (PQ) method for each benthic component on the three reef types.

Benthic components shown are (A) hard corals, (B) sponges, (C) gorgonians, (D) macroalgae, (E) turf algae and (F) crustose coralline algae. Pearson correlation coefficients are also shown along with their corresponding $p$-values $(n=21)$.
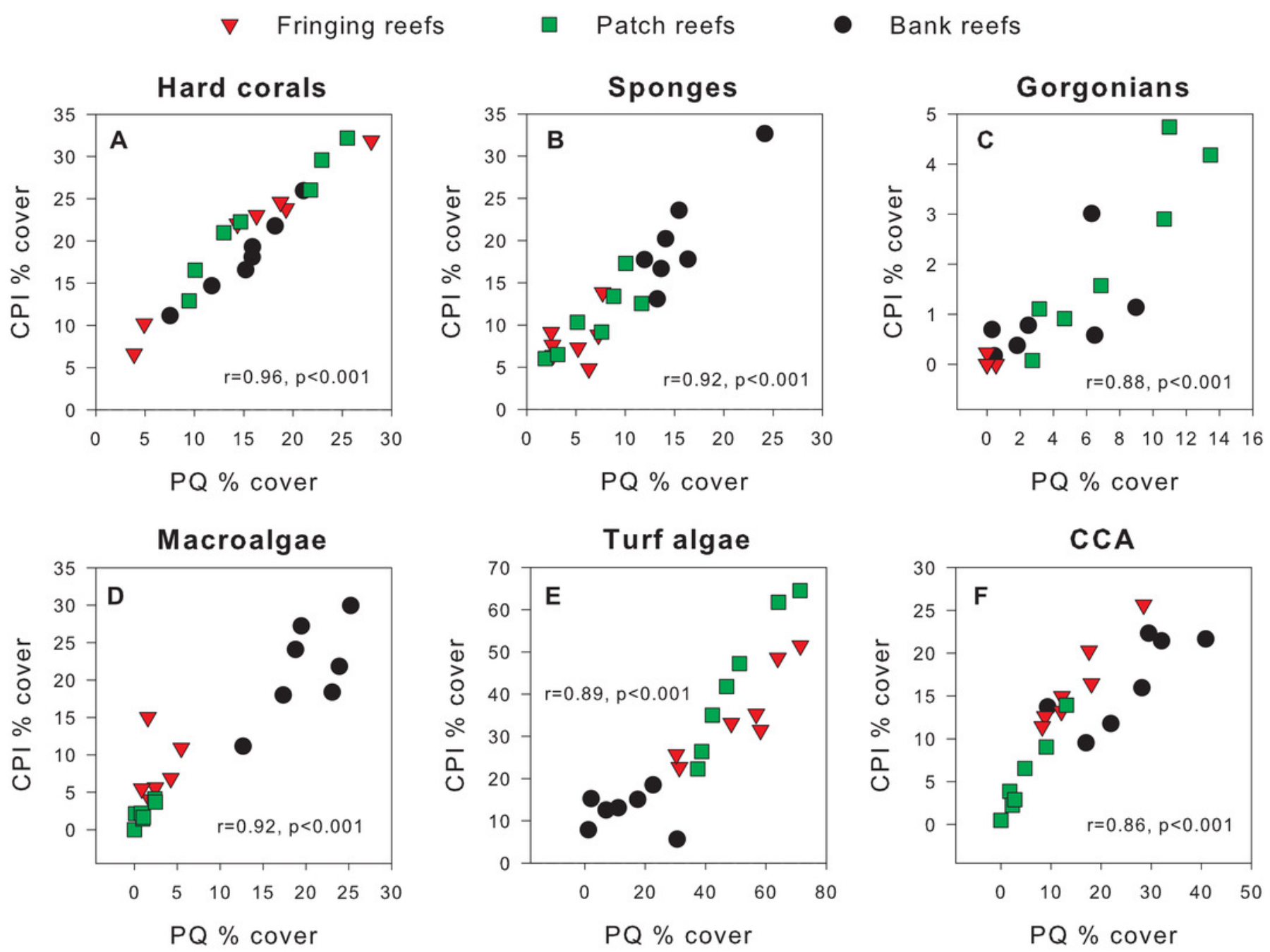
Figure 4

Differences in percent cover estimates between methods against the average percent cover estimated by both methods for each benthic component across the three reef types in Barbados.

Benthic components shown are (A) hard corals, (B) sponges, (C) gorgonians, (D) macrolagae, (E) turf algae and (F) crustose coralline algae. Each panel shows site-specific values (left) and averages for each reef type (right) with corresponding 95\% bootstrap confidence intervals $(n=7)$.

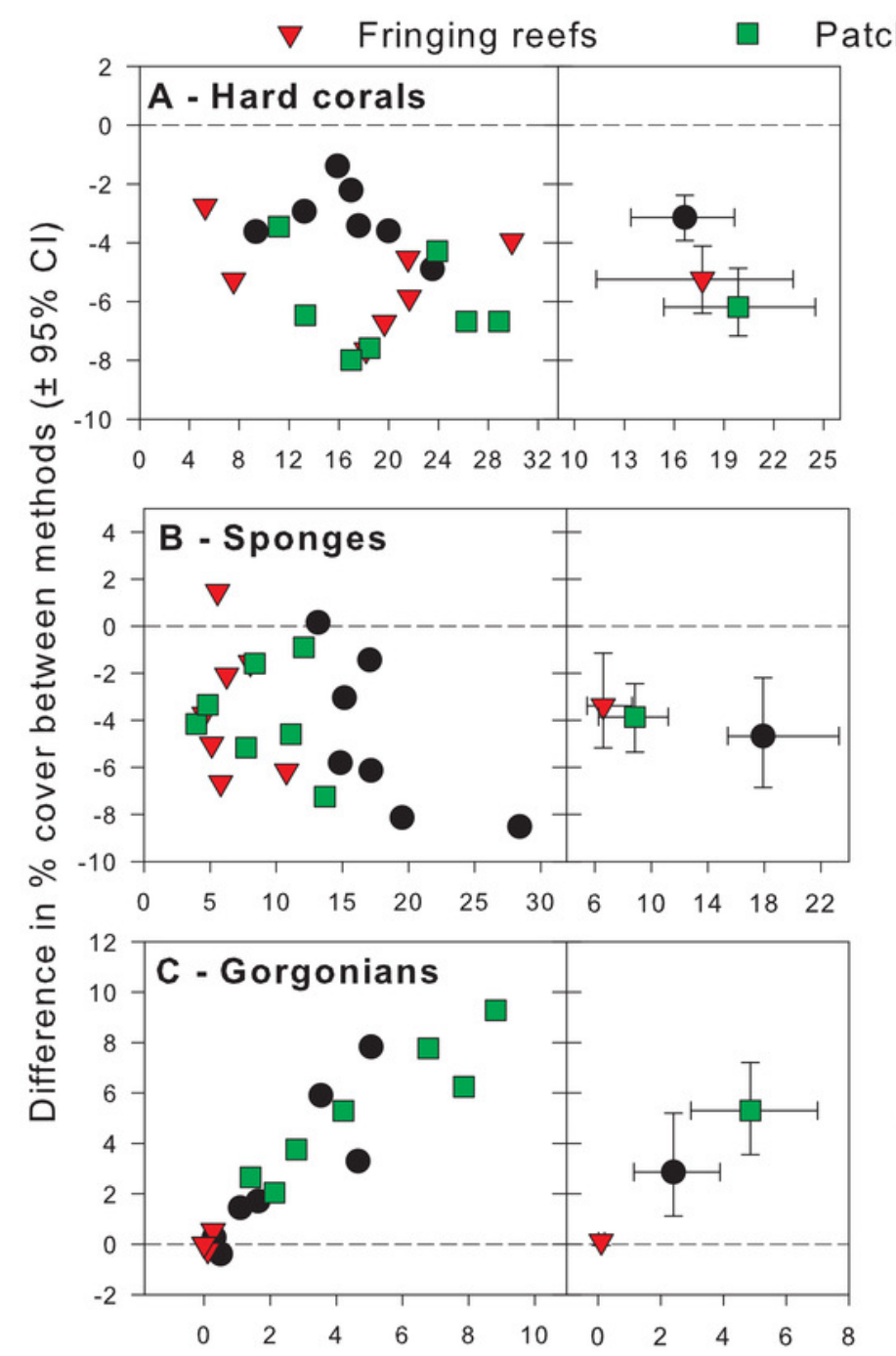

Average $\%$ cover of both methods ( $\pm 95 \% \mathrm{CI}$ )
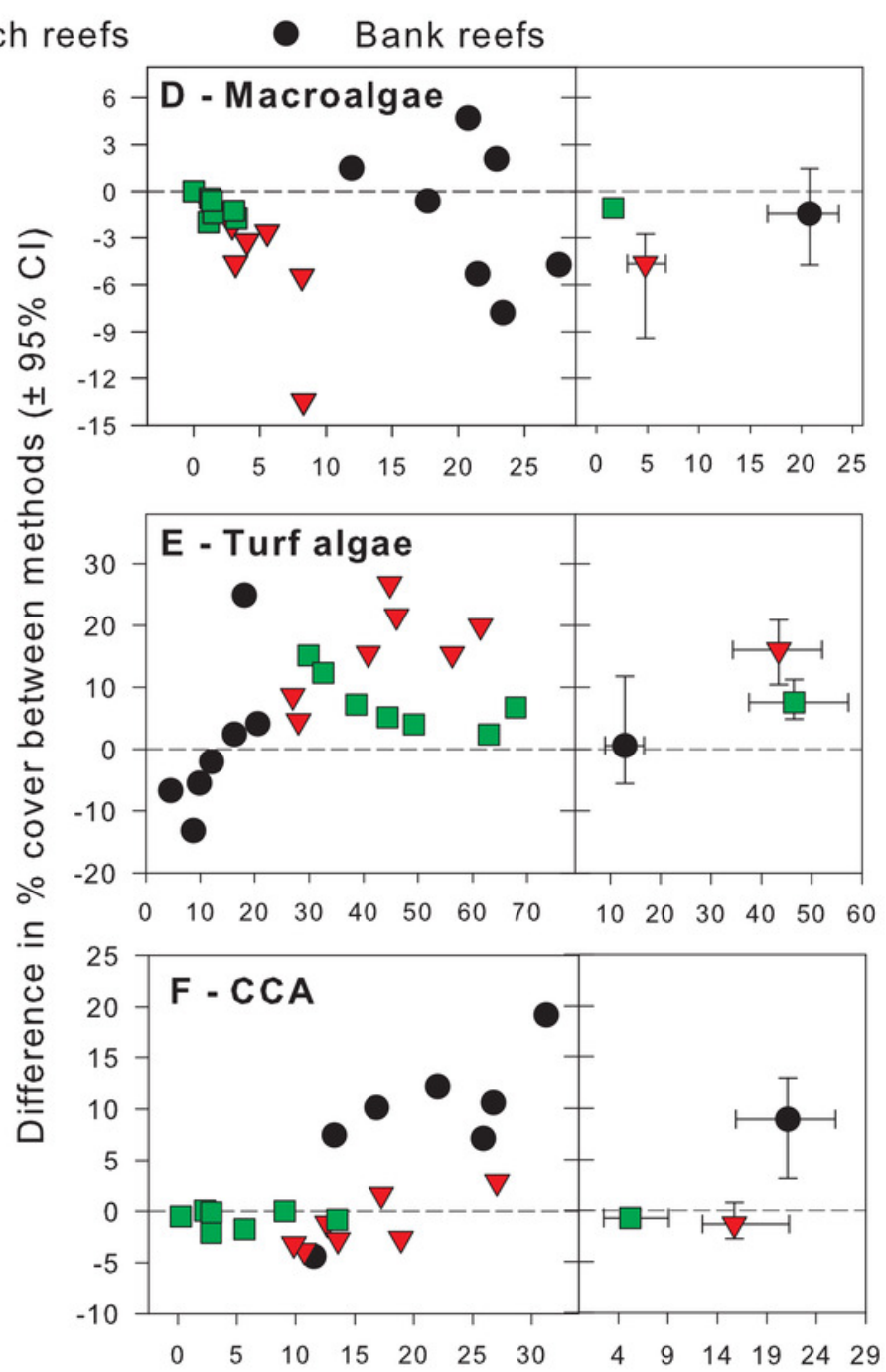

Average \% cover of both methods ( $\pm 95 \% \mathrm{Cl}$ ) 


\section{Figure 5}

Changes in absolute hard coral percent cover between 2012 and 2017 estimated by comparing data from 2012 obtained using the chain point-intercept (CPI) method with method-specific data sets from 2017.

Comparisons are shown between 2012 CPI data and (A) 2017 CPI data, (B) 2017 PQ data, and (C) 2017 PQ data converted to CPI. Data are for the 21 reef survey sites. The horizontal reference line indicates zero change. A median test (after combining data from all reef types) confirms that the median change between 2012 and 2017 is statistically significant (i.e. different from zero) in all three temporal comparisons (all cases: $W \geq 47, n=21, p \leq 0.017$ ). 


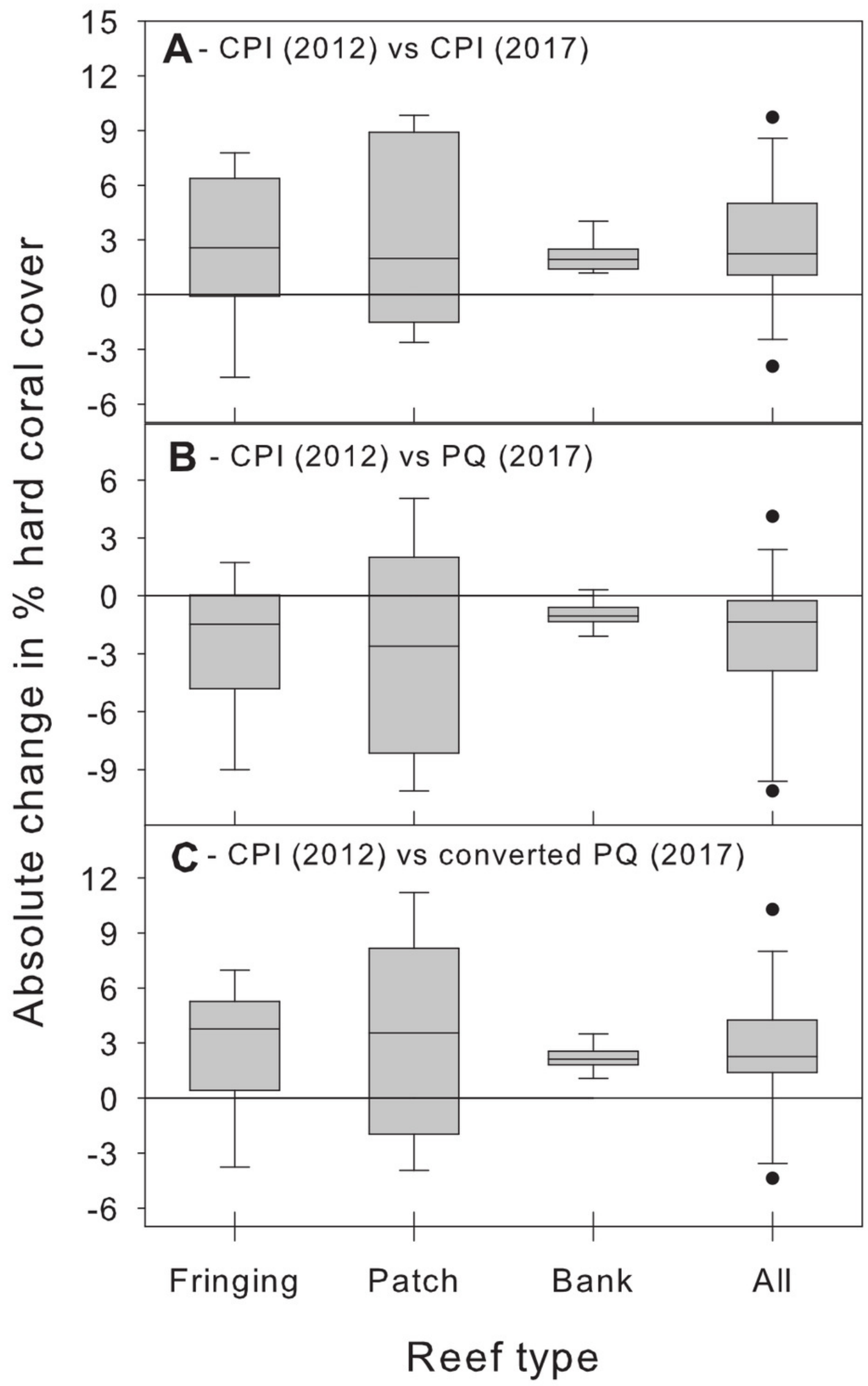




\section{Table $\mathbf{1}$ (on next page)}

Summary of the ANCOVA full model results for each benthic component, comparing difference in percent cover as a function of reef type and average percent cover.

Models use the differences in \% cover between methods as a response variable, and reef type (categorical) and the average \% cover obtained from both methods (numerical) as predictors, along with their interaction. Bold font indicates significant terms $(p<0.05)$. See Table 2 for the interpretation of these findings. CCA is crustose coralline algae. 


\begin{tabular}{llcccc}
\hline Benthic & Term & $\begin{array}{c}\text { d.f. } \\
\text { num }\end{array}$ & $\begin{array}{c}\text { d.f. } \\
\text { den }\end{array}$ & F statistic & P-value \\
\hline Hard corals & Intercept & 1 & 15 & 180.91 & $<\mathbf{0 . 0 0 1}$ \\
& Reef type & 2 & 15 & 8.36 & $\mathbf{0 . 0 0 4}$ \\
& Average cover & 1 & 15 & 1.22 & 0.288 \\
& Reef type x Average cover & 2 & 15 & 0.09 & 0.915 \\
\hline Sponges & Intercept & 1 & 15 & 50.02 & $<\mathbf{0 . 0 0 1}$ \\
& Reef type & 2 & 15 & 0.41 & 0.673 \\
& Average cover & 1 & 15 & 4.27 & 0.057 \\
& Reef type x Average cover & 2 & 15 & 0.58 & 0.573 \\
\hline \multirow{2}{*}{ Gorgonians } & Intercept & 1 & 15 & 23.97 & $<\mathbf{0 . 0 0 1}$ \\
& Reef type & 2 & 15 & 101.00 & $<\mathbf{0 . 0 0 1}$ \\
& Average cover & 1 & 15 & 62.48 & $<\mathbf{0 . 0 0 1}$ \\
& Reef type x Average cover & 2 & 15 & 2.45 & 0.120 \\
\hline \multirow{2}{*}{ Macroalgae } & Intercept & 1 & 15 & 27.61 & $<\mathbf{0 . 0 0 1}$ \\
& Reef type & 2 & 15 & 4.74 & $\mathbf{0 . 0 2 5}$ \\
& Average cover & 1 & 15 & 8.37 & $\mathbf{0 . 0 1 1}$ \\
& Reef type x Average cover & 2 & 15 & 1.21 & 0.324 \\
\hline \multirow{2}{*}{ Turf algae } & Intercept & 1 & 15 & 65.55 & $<\mathbf{0 . 0 0 1}$ \\
& Reef type & 2 & 15 & 7.89 & $\mathbf{0 . 0 0 5}$ \\
& Average cover & 1 & 15 & 1.15 & 0.301 \\
& Reef type x Average cover & 2 & 15 & 7.07 & $\mathbf{0 . 0 0 7}$ \\
\hline \multirow{2}{*}{ CCA } & Intercept & 1 & 15 & 3.93 & $\mathbf{0 . 0 6 6}$ \\
& Reef type & 2 & 15 & 13.31 & $<\mathbf{0 . 0 0 1}$ \\
& Average cover & 1 & 15 & 5.34 & $\mathbf{0 . 0 3 5}$ \\
& Reef type x Average cover & 2 & 15 & 5.23 & $\mathbf{0 . 0 1 9}$ \\
\hline & & & & &
\end{tabular}




\section{Table 2 (on next page)}

Summary of conclusions from the comparisons of percent cover estimates between chain point-intercept (CPI) and photoquadrat (PQ) methods for six benthic components on the three reef types in Barbados.

The corresponding formulae to convert percent cover between methods is shown for each benthic component at each reef type (last two columns). Benthic components are ordered (from top to bottom) by increasing complexity in the pattern of differences between methods. CCA is crustose coralline algae. 


\begin{tabular}{|c|c|c|c|}
\hline $\begin{array}{l}\text { Benthic } \\
\text { component }\end{array}$ & Conclusion & Reef type & Conversion formulae \\
\hline \multirow{3}{*}{ Sponges } & \multirow{3}{*}{$\begin{array}{l}\text { Systematic differences in } \% \text { cover between } \\
\text { methods that do not depend on reef type and } \\
\text { which do not scale with } \% \text { cover }\end{array}$} & Fringing & $\mathrm{CPI}=3.90+\mathrm{PQ}$ \\
\hline & & Patch & $\mathrm{CPI}=3.90+\mathrm{PQ}$ \\
\hline & & Bank & $\mathrm{CPI}=3.90+\mathrm{PQ}$ \\
\hline \multirow[t]{3}{*}{ Hard corals } & \multirow{3}{*}{$\begin{array}{l}\text { Systematic differences in \% cover between } \\
\text { methods that depend on reef type, but which } \\
\text { do not scale with \% cover }\end{array}$} & Fringing & $\mathrm{CPI}=5.24+\mathrm{PQ}$ \\
\hline & & Patch & $\mathrm{CPI}=6.16+\mathrm{PQ}$ \\
\hline & & Bank & $\mathrm{CPI}=3.15+\mathrm{PQ}$ \\
\hline \multirow[t]{3}{*}{ Macroalgae } & \multirow{3}{*}{$\begin{array}{l}\text { Systematic differences in \% cover between } \\
\text { methods that depend on reef type and which } \\
\text { scale with \% cover in a manner that is } \\
\text { consistent among reef types }\end{array}$} & Fringing & $\mathrm{CPI}=3.07+1.65 \times \mathrm{PQ}$ \\
\hline & & Patch & $\mathrm{CPI}=0.37+1.65 \times \mathrm{PQ}$ \\
\hline & & Bank & $\mathrm{CPI}=-11.48+1.65 \times \mathrm{PQ}$ \\
\hline \multirow[t]{3}{*}{ Gorgonians } & \multirow{3}{*}{$\begin{array}{l}\text { Systematic differences in \% cover between } \\
\text { methods that depend on reef type and which } \\
\text { scale with \% cover in a manner that is } \\
\text { consistent among reef types }\end{array}$} & Fringing & $\mathrm{CPI}=-0.03+0.36 \times \mathrm{PQ}$ \\
\hline & & Patch & $\mathrm{CPI}=-0.45+0.36 \times \mathrm{PQ}$ \\
\hline & & Bank & $\mathrm{CPI}=-0.39+0.36 \times \mathrm{PQ}$ \\
\hline \multirow[t]{3}{*}{ CCA } & \multirow{3}{*}{$\begin{array}{l}\text { Systematic differences in \% cover between } \\
\text { methods that depend on reef type and which } \\
\text { scale with \% cover in a manner that differs } \\
\text { among reef types }\end{array}$} & Fringing & $\mathrm{CPI}=5.71+0.71 \times \mathrm{PQ}$ \\
\hline & & Patch & $\mathrm{CPI}=0.74+1.00 \times \mathrm{PQ}$ \\
\hline & & Bank & $\mathrm{CPI}=4.81+0.46 \times \mathrm{PQ}$ \\
\hline \multirow[t]{3}{*}{ Turf algae } & \multirow{3}{*}{$\begin{array}{l}\text { Systematic differences in \% cover between } \\
\text { methods that depend on reef type and which } \\
\text { scale with \% cover in a manner that differs } \\
\text { among reef types }\end{array}$} & Fringing & $\mathrm{CPI}=0.62+0.67 \times \mathrm{PQ}$ \\
\hline & & Patch & $\mathrm{CPI}=-20.80+1.26 \times \mathrm{PQ}$ \\
\hline & & Bank & $\mathrm{CPI}=10.84+0.13 \times \mathrm{PQ}$ \\
\hline
\end{tabular}

